\title{
Clinical Awareness and Acceptance of Sonographically Diagnosed Epiploic Appendagitis (EA): A Retrospective Analysis of EA in a Single Tertiary Academic Referral Center
}

\section{(ㄷ) (1) (우) $\odot$}

\section{Authors}

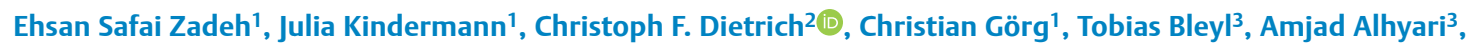
Corinna Trenker ${ }^{4}$

\section{Affiliations}

1 Interdisciplinary Center of Ultrasound Diagnostics, University Hospital of Giessen and Marburg, Campus Marburg, Marburg, Germany

2 Department of General Internal Medicine, Hirslanden Klinik Beau-Site, Bern, Switzerland

3 Gastroenterology, Endocrinology, Metabolism and Clinical Infectiology, University Hospital of Giessen and Marburg, Campus Marburg, Marburg, Germany

4 Haematology, Oncology and Immunology, University Hospital of Giessen and Marburg, Campus Marburg, Marburg, Germany

Key words

epiploic appendagitis, abdominal ultrasonography, CEUS, clinical awareness, clinical acceptance

received 24.11.2020

accepted after revision 24.01.2021

published online 2021

\section{Bibliography}

Ultrasound Int Open 2021; 7: E87-E93

DOI 10.1055/a-1371-9359

ISSN 2199-7152

(c) 2021. The Author(s).

This is an open access article published by Thieme under the terms of the Creative Commons Attribution-NonDerivative-NonCommercial-License, permitting copying and reproduction so long as the original work is given appropriate credit. Contents may not be used for commecial purposes, or adapted, remixed, transformed or built upon. (https://creativecommons. org/licenses/by-nc-nd/4.0/)

Georg Thieme Verlag KG, Rüdigerstraße 14,

70469 Stuttgart, Germany

Correspondence

Christian Görg

Interdisciplinary Center of Ultrasound Diagnostics,

University Hospital, Giessen and Marburg,

Baldingerstrasse

35043 Marburg

Germany

Tel.: 06421-2863691, Fax: 06421-2866358

goergc@med.uni-marburg.de

\section{ABSTRACT}

Purpose To describe the clinical awareness and acceptance of ultrasound-diagnosed acute epiploic appendagitis (EA) and their importance to avoid unnecessary therapeutic and imaging measures.

Patients and Methods The data were obtained of $n=54$ patients with acute, localized, peritonitic pain and EA diagnosed by $\mathrm{B}$-mode ultrasound and contrast-enhanced ultrasound examination from November 2003 to September 2020. All examinations were performed by a German Society for Ultrasound in Medicine (DEGUM) Level III qualified examiner. Based on documentation by the treating physicians, the clinical awareness and acceptance of EA diagnosis was determined in all patients and compared between subgroups diagnosed before 2013 and from 2013 onwards. In 2013, a local educational training program regarding the diagnosis of and therapy for EA was initiated for physicians.

Results In all patients, EA was sonographically diagnosed by a DEGUM level III qualified examiner. At enrollment, EA was mentioned as a suspected clinical diagnosis in $n=1 / 54(1.9 \%)$ patient. Furthermore, in $n=39 / 54$ (72.2\%) cases, the EA was documented and accepted by the treating physicians at the time of patient discharge as the final clinical diagnosis. The clinical acceptance was significantly higher from 2013 onwards compared with before 2013 ( $p<0.05$ ). Moreover, in $n=26 / 54$ (48.1\%) patients, unnecessary therapeutic measures were initiated, with no significant difference between pre-2013 and post-2013 numbers ( $p>0.05)$.

Conclusion In our retrospective study, we showed that awareness and acceptance of the disease EA are low. Low diagnostic acceptance of EA by the clinician leads to unnecessary therapeutic and imaging measures and is a general problem related to rare diseases in the healthcare system. 


\section{Introduction}

Johann Wolfgang von Goethe (1749-1832) remarked in a conversation with the chancellor of Saxe-Weimar-Eisenach, Friedrich v. Müller (1779-1849), "You only see what you already know and understand" [1]. In medicine, this means that you cannot recognize, name, or treat conditions without knowledge of disease phenomena. For genetically determined, chronic, life-threatening, rare diseases, the term "orphan diseases" was introduced and, in this context, centers for rare and undiagnosed diseases have been established [2,3]. In addition, rare, non-genetically caused, acquired diseases such as epiploic appendagitis (EA), which are often not diagnosed or are misdiagnosed and therefore place an unnecessary burden on the healthcare system, present a diagnostic challenge in clinical medicine [4]. In an unpublished survey of internal assistants at a university hospital, $90 \%$ did not know the clinical presentation of EA. In 902 patients investigated by computed tomography $(\mathrm{CT})$ because of abdominal pain, the frequency of EA was estimated at $1.3 \%$, with an incidence of 8.8 cases/million/year, according to a retrospective analysis [5]. Moreover, in patients with primarily diagnosed diverticulitis, approximately $7 \%$ of cases definitively had EA [6].

The epiploic appendages are fat pendants of the colon that originate from the serosal surface [7]. An unfixed end of the appendices epiploicae and consequently increased mobility can lead to spontaneous torsion with the development of infarction (EA) [8, 9]. The clinical presentation of EA is strictly localized peritonitic pain, which is more frequent on the left than on the right side and does not differ from the clinical presentation of left-sided acute diverticulitis (AD) and right-sided acute appendicitis (AA) [10,11]. For this reason, the initial referral diagnosis is incorrect in almost all patients with a final diagnosis of EA $[12,13]$. These patients are usually afebrile and occasionally suffer from vomiting or diarrhea [10]. In comparison with the differential diagnosis of $A D$, patients with EA are usually younger $[12,14]$. Furthermore, patients with EA show no or only mildly increased inflammatory parameters, such as a moderate increase in $\mathrm{C}$-reactive protein (CRP), in comparison with patients with $A D$ and $A A$ [11]. The symptoms of $E A$, which is a self-limiting disease, can persist for up to 7 days in follow-up examinations [10]. Due to the non-specific clinical symptoms, the diagnosis can be made only by imaging methods $[9,11,15]$.

Computed tomography imaging is considered to be the highest priority imaging in surgery to clarify acute abdominal pathologies [16]. It has already been shown that EA can be diagnosed by CT and differentiated from $\operatorname{AD}[15,17]$. However, the rarity of the disease combined with the low awareness of EA leads to a high rate of CT misdiagnoses even by radiologists [4]. Rao et al. reported in a retrospective study that $64 \%$ of cases were overlooked in CT examinations [4]. However, ultrasound should be used in non-critical patients for better efficiency and targeted use of CT examination [16]. Even in rare congenital and acquired abdominal diseases, ultrasound patterns have already been described [18-26].

In 2002, Hollerweger et al. described the characteristic features of EA in B-mode ultrasound (B-US) and color Doppler sonography (CDS) [9]. In B-US, EA appears as an echogenic, non-compressible lesion in real-time examination that is located adjacent to the colon and is adherent to the abdominal wall $[9,21]$. In CDS, the lesions show a lack of central color flow due to a perfusion deficit caused by the infarction [9]. As another noninvasive method for the diagnosis of perfusion disorders, contrast-enhanced ultrasound (CEUS) is routinely established in clinical practice [27]. Görg et al. demonstrated the absence of central enhancement of the echogenic lesions on CEUS and proved this to be a typical pattern for EA on CEUS [11]. Based on this data, ultrasound seems to be a potential "gold standard" for the diagnosis of EA [9, 11, 21]. In 2019, the EFSUMB Gastrointestinal Ultrasound (GIUS) Task Force Group published guidelines for rare gastrointestinal diseases and described a high level of agreement regarding the ultrasound characteristics of EA [21].

This study aims to describe the clinical awareness and acceptance of ultrasound-diagnosed acute EA and their importance to avoid unnecessary therapeutic and imaging measures over a period of 17 years in a university hospital.

\section{Patients and Methods}

The data of 54 consecutive primarily outpatients with acute, localized, peritonitic pain and EA diagnosed by B-US and CEUS examination according to the EFSUMB guidelines from November 2003 to September 2020 were retrospectively analyzed [27]. The 54 study patients had a mean age of 41.1 years (range: $10-80$ years, standard deviation: 17 years). 37 patients were male, and 17 patients were female The data from 15 of these patients were published in a previous report from our group [11]. All examinations were performed by a German Society for Ultrasound in Medicine (DEGUM) Level III qualified examiner. Diagnosis of EA was indicated on B-US by an echogenic, non-compressible lesion in real-time examination adjacent to the colon, adhering to the abdominal wall ( $\triangleright$ Figa. 1a and $\mathbf{1 b}$ ) and on CEUS by marked contrast enhancement of the lesion with a central area of non-enhancement ( $\triangleright$ Fig. 1c and 1d) $[9,11]$.

Furthermore, a sonographic and clinical follow-up was performed in 45/54 (83.3\%) cases. In all of these cases, the diagnosis of EA was confirmed by documented regression of clinical symptoms and sonographic pathology without the occurrence of alternative diagnoses. The following clinical, laboratory, and imaging data of the patients were evaluated retrospectively. Furthermore, the clinical awareness and acceptance of EA diagnoses were determined in all study patients based on the documentation generated by treating physicians. In 2013, an educational training program regarding the diagnosis and treatment of EA was initiated. Therefore, the study period was divided into two segments (before 2013 and from 2013 onwards), and the clinical and imaging data were compared between subgroups diagnosed before $2013(n=22)$ and from 2013 onwards $(n=32)$.

\section{Clinical Data}

Clinical awareness

Clinical awareness of EA was defined as considering EA as a possible differential diagnosis and was evaluated based on documented suspected clinical diagnosis upon admission of the patient to the hospital. 


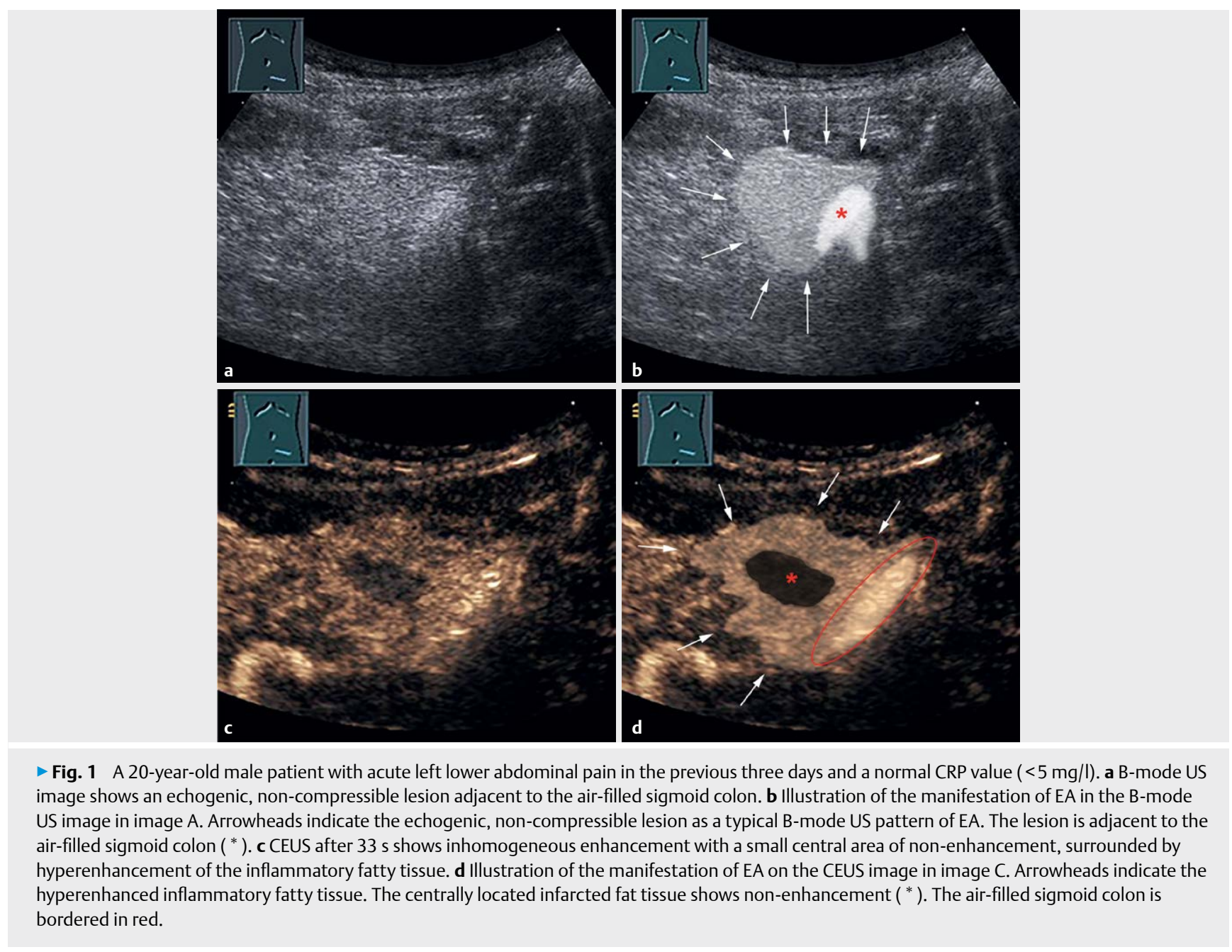

\section{Clinical and laboratory manifestations}

- Distribution of the location of pain.

- CRP value (normal range $<5 \mathrm{mg} / \mathrm{l}$ ).

Initial basic ultrasound examination

Frequency of performance and documented diagnoses of an initial basic ultrasound examination.

\section{Computed tomography and magnetic resonance imaging data}

Frequency of performance, date of examination in comparison with reference ultrasound, and documented diagnoses by a CT or magnetic resonance imaging (MRI) examination.

\section{Clinical acceptance}

Clinical acceptance of EA was defined as accepting sonographically diagnosed EA by a DEGUM level III qualified examiner as the final diagnosis. The difference between the finally documented ultrasound diagnosis of EA by a DEGUM level III qualified examiner and the documented definitive clinical diagnosis by the treating physician at the time of the patient's discharge from the hospital was used to determine the clinical acceptance of the final sonographic diagnosis.

\section{Treatment data}

- Frequency of hospitalization (number of inpatient admissions).

- Frequency of prescription of antibiotic therapy.

\section{Statistical analysis}

Statistical analysis was carried out with Fisher's exact test. A p-value of $<0.05$ was defined as significant.

\section{Results}

In all study patients, EA was sonographically detected and diagnosed by a DEGUM level III qualified examiner.

\section{Clinical awareness}

- Table 1 presents the clinically suspected diagnosis at the time of admission of the patient to the hospital for all study patients. In one case (after 2013), EA was stated as a suspected clinical diagnosis (1.9\%). 


\section{Clinical and laboratory manifestations}

All patients had strictly localized peritonitic pain at the site of the sonographically detected pathology. The pain in the study patients was localized in the left lower abdomen in 37/54 (68.5\%), in the right lower abdomen in 6/54 (11.1\%), in the left upper abdomen in $5 / 54$ (9.3\%), in the right upper abdomen in 3/54 (5.6\%), and in the middle of the abdomen in 3/54 (5.6\%) patients. $21 / 54$ (38.9\%) patients had a normal CRP value ( $<5 \mathrm{mg} / \mathrm{l})$, and $31 / 54(57.4 \%)$ had a minimally increased CRP value with values between 5 and $30 \mathrm{mg} / \mathrm{l}$. Two (3.7\%) patients had levels above $30 \mathrm{mg} / \mathrm{l}$.

\section{Initial basic ultrasound examination}

In 20/54 (37\%) patients, an initial basic ultrasound examination was performed before the final ultrasound examination by a DEGUM level III qualified examiner with a diagnosis of EA. The frequency of initial basic ultrasound examination was 6/22 (27.3\%) before 2013 and 14/32 (43.8\%) from 2013 onwards ( The frequency of initial basic ultrasound diagnostics was not significantly different before 2013 and from 2013 onwards ( $p=0.262$, Fisher's exact test). In 2/20 (10\%) patients, EA was detected in basic ultrasound, and in 18/20 (90\%) EA was not detected. The following findings were documented during the basic ultrasound exam-

- Table 1 Clinical awareness of EA at admission (54 patients with sonographically diagnosed EA).

\begin{tabular}{|c|c|c|c|}
\hline $\begin{array}{l}\text { Clinically } \\
\text { suspected } \\
\text { diagnosis } \\
n=54(100 \%)\end{array}$ & $\begin{array}{l}\text { All study } \\
\text { patients } \\
n=54 \\
(100 \%)\end{array}$ & $\begin{array}{l}\text { Study } \\
\text { patients } \\
\text { before } 2013 \\
n=22 \\
(40.7 \%)\end{array}$ & $\begin{array}{l}\text { Study } \\
\text { patients from } \\
2013 \\
\text { onwards } \\
n=32 \\
(59.3 \%)\end{array}$ \\
\hline $\begin{array}{l}\text { Epiploic } \\
\text { appendagitis }\end{array}$ & $1(1.9 \%)$ & $0(0 \%)$ & $1(3.1 \%)$ \\
\hline Diverticulitis & 39 (74.1\%) & $16(72.7 \%)$ & $24(75.0 \%)$ \\
\hline Appendicitis & $7(13.0 \%)$ & $4(18.2 \%)$ & $3(9.4 \%)$ \\
\hline Gastroenteritis & $2(3.7 \%)$ & $1(4.5 \%)$ & $1(3.1 \%)$ \\
\hline Colitis & $2(3.7 \%)$ & $1(4.5 \%)$ & $1(3.1 \%)$ \\
\hline Cholecystitis & 1 (1.9\%) & $0(0 \%)$ & $1(3.1 \%)$ \\
\hline Adhesive ileus & $1(1.9 \%)$ & $0(0 \%)$ & $1(3.1 \%)$ \\
\hline
\end{tabular}

ination: 5/18 (27.8\%) cases with no pathology; 4/18 (22.2\%) cases of bowel wall thickening; $2 / 18(11.1 \%)$ cases of sigmoid diverticulitis; $2 / 18$ (11.1\%) cases of an echogenic formation; $1 / 18$ (5.6\%) case of a hypoechoic formation; $1 / 18$ (5.6\%) case of segmental inflammation of the colon; $1 / 18$ (5.6\%) case of free abdominal fluid; $1 / 18(5.6 \%)$ case of cholecystitis; and $1 / 18$ (5.6\%) case of a cockade sign in the colon; $1 / 18$ (5.6\%).

\section{Computed tomography and magnetic resonance imaging data}

In all patients, clinical suspicion of sigmoid diverticulitis was documented as the indication for CT and MRI examinations. In total, $n=15 / 54(27.8 \%)$ patients had a CT examination, $(n=9 / 22$ [40.9\%] before 2013; $n=6 / 32$ [18.8\%] 2013 onwards) $\triangleright$ Table 2 . The frequency of performed CT examinations was not significantly different before 2013 and from 2013 onwards ( $p=0.225$, Fisher's exact test). Computed tomography was initiated before $(n=8 / 15,53.3 \%)$ or after $(n=7 / 15,46.7 \%)$ the documented final reference ultrasound examination. In CT examinations, the following findings were reported: $n=5 / 15$ (33.3\%) cases of EA; $n=4 / 15$ (26.7\%) cases with no pathology; $n=2 / 15$ (13.3\%) cases of diverticulitis; $n=1 / 15$ $(6.7 \%)$ cases of gastroenteritis; $n=1 / 15$ (6.7\%) cases of lymphadenitis mesenterica; $n=1 / 15$ (6.7\%) cases of suspected colon perforation; and $n=1 / 15$ (6.7\%) cases of colitis. An MRI examination was performed in $n=1 / 32$ (3.1\%) patient after 2013, and EA was diagnosed ( $\triangleright$ Table 2 ).

\section{Clinical acceptance}

In a total of $n=39 / 54$ (72.2\%) cases, EA was documented as the final clinical diagnosis, and, in $n=15 / 54$ (27.8\%) cases, diagnoses other than EA were documented as the final diagnosis at the time of patient discharge despite confirmation of the EA diagnosis by a DEGUM level III qualified examiner ( $\triangleright$ Table 3$)$. Of these patients, $n=7 / 15(46.7 \%)$ had a normal CRP value $(<5 \mathrm{mg} / \mathrm{l})$, and $n=8 / 15$ (53.3\%) had a minimally increased CRP value of between 5 and $30 \mathrm{mg} / \mathrm{l}$. Furthermore, a clinical and sonographic follow-up was performed in $n=14 / 15$ (93.3\%) patients, and the diagnosis of EA was confirmed with clinical and sonographic regression with no evidence of an alternative diagnosis.

Before 2013 in $n=12 / 22$ (54.5\%) and from 2013 onwards in $n=27 / 32(84.4 \%)$ patients, the final clinical diagnosis of EA was documented and accepted by the treating physician at the time of patient discharge ( $>$ Fig. 2). Clinical acceptance was significantly

- Table 2 Diagnostic data (54 patients with sonographically diagnosed EA).

\begin{tabular}{|l|l|l|l|l|}
\hline Diagnostic measures & $\begin{array}{l}\text { All patient } \\
\boldsymbol{n = 5 4}(\mathbf{1 0 0} \%)\end{array}$ & $\begin{array}{l}\text { Study patients before } \\
\mathbf{2 0 1 3} \mathbf{n = 2 2}(\mathbf{4 0 . 7} \%)\end{array}$ & $\begin{array}{l}\text { Study patients from 2013 } \\
\text { onwards } \boldsymbol{n = 3 2} \text { (59.3\%) }\end{array}$ & $\begin{array}{l}\text { Diagnosis of EA } \\
\text { detected or } \\
\text { confirmed }\end{array}$ \\
\hline Initial basic ultrasound examination & $20(37 \%)$ & $6(27.3 \%)$ & $14(43.8 \%)$ & $2 / 20(10 \%)$ \\
\hline Computed tomography & $15(27.8 \%)$ & $9(40.9 \%)$ & $6(18.8 \%)$ & $5 / 15(33.3 \%)$ \\
\hline Magnetic resonance imaging & $1(1.9 \%)$ & $0(0 \%)$ & $1(3.1 \%)$ & $1 / 1(100 \%)$ \\
\hline Follow-up & $45(83.3 \%)$ & $20(90.9 \%)$ & $25(78.1 \%)$ & $45 / 45(100 \%)$ \\
\hline
\end{tabular}


- Table 3 Clinical acceptance of EA as final diagnosis (54 patients with sonographically diagnosed EA).

\begin{tabular}{|c|c|c|c|}
\hline Final clinical diagnosis $n=54(100 \%)$ & $\begin{array}{l}\text { All study patients } \\
n=54(100 \%)^{*}\end{array}$ & $\begin{array}{l}\text { Study patients before } 2013 \\
n=22(40.7 \%)\end{array}$ & $\begin{array}{l}\text { Study patients from } 2013 \text { onwards } \\
n=32(59.3 \%)\end{array}$ \\
\hline Epiploic appendagitis & $39(72.2 \%)$ & $12(54.5 \%)$ & $27(84.4 \%)$ \\
\hline Unclear abdominal pain & $10(18.5 \%)$ & $7(31.8 \%)$ & $3(9.4 \%)$ \\
\hline Diverticulitis & $3(5.5 \%)$ & $1(4.5 \%)$ & $2(6.3 \%)$ \\
\hline Gastroenteritis & $1(1.9 \%)$ & $1(4.5 \%)$ & $0(0 \%)$ \\
\hline Colitis & $1(1.9 \%)$ & $1(4.5 \%)$ & $0(0 \%)$ \\
\hline
\end{tabular}

- Table 4 Therapeutic data (54 patients with sonographically diagnosed EA).

\begin{tabular}{|l|l|l|l|}
\hline Therapeutic measures & $\begin{array}{l}\text { All study patients } \\
\boldsymbol{n}=\mathbf{5 4}(\mathbf{1 0 0} \%)\end{array}$ & $\begin{array}{l}\text { Study patients before } \mathbf{2 0 1 3} \\
\mathbf{n = 2 2}(\mathbf{4 0 . 7} \%)\end{array}$ & $\begin{array}{l}\text { Study patients from 2013 onwards } \\
\boldsymbol{n = 3 2}(\mathbf{5 9 . 3} \%)\end{array}$ \\
\hline Hospitalization & $23(\mathbf{4 2 . 6 \% )}$ & $14(63.6 \%)$ & $9(28.1 \%)$ \\
\hline Antibiotic therapy & $15(\mathbf{2 7 . 8 \% )}$ & $7(31.8 \%)$ & $8(25.0 \%)$ \\
\hline
\end{tabular}

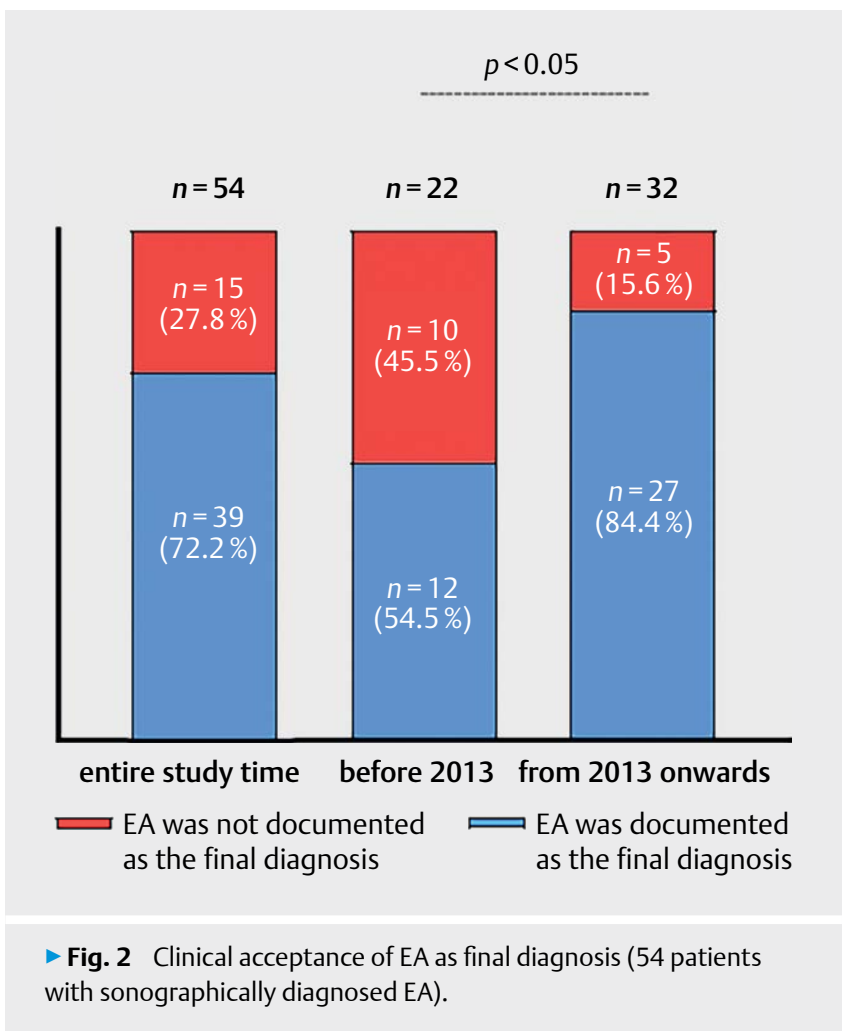

higher from 2013 onwards compared with before 2013 ( $p<0.05$, Fisher's exact test).

\section{Treatment data}

In 28/54 (51.9\%) cases, the patients received symptomatic therapy with analgesics. In 26/54 (48.1\%) patients, therapy was initiated, including hospitalization (inpatient admission) ( $n=23 / 54$ [42.6\%]) and antibiotic therapy (15/54 [27.8\%]). In 4/54 (7.4\%) patients, antibiotic therapy was recommended despite the acceptance of EA in the final clinical diagnosis. Hospitalization was necessary in 14/22 (63.6\%) patients before 2013 and in 9/32 (28.1\%) patients from 2013 onwards ( $\triangleright$ Table 4). The frequency of hospitalization was significantly lower from 2013 onwards than before 2013 $(p<0.05$, Fisher's exact test). Furthermore, antibiotic therapy was administered to $7 / 22$ (31.8\%) patients before 2013 and to 9/32 (28.1\%) patients from 2013 onwards ( $\triangleright$ Table 4$)$. The frequency of the administration of antibiotic therapy was not significantly different before 2013 and from 2013 onwards ( $p=0.772$, Fisher's exact test).

\section{Follow-up}

In 45/54 (83.3\%) patients, clinical and sonographic follow-up was performed (20/22 [90.9\%] before 2013; 25/32 [78.1\%] 2013 onwards). The frequency of performed clinical and sonographic follow-up was not significantly different before 2013 and from 2013 onwards ( $p=0.283$, Fisher's exact test).

\section{Discussion}

This retrospective study investigated the clinical awareness and acceptance of sonographically diagnosed EA in 54 consecutive patients diagnosed by a DEGUM level III qualified examiner during a period of 17 years in a university hospital. Our results revealed that 
the level of awareness about the disease EA is extremely low. Only in $n=1 / 54$ (1.9\%) patient was EA considered as a suspected diagnosis at the time of hospital admission. Therefore, attending physicians must be alerted to the potential differential diagnosis of EA in patients with corresponding symptoms for the targeted use of diagnostic procedures. In accordance with previous studies, the study patients were more frequently male and middle-aged adults in comparison with patients with AD [28]. All patients reported acute localized abdominal pain, often localized in the left lower abdomen, with missing or mildly increased inflammation parameters in contrast to severe increased inflammatory parameters in patients with similar clinical symptoms but with AD [12]. These characteristic features have been described previously in several studies and should prompt the physician to consider the disease of EA [4, 1012, 14, 28].

As shown in previous research, high-quality ultrasound in combination with CEUS and clinical and laboratory data enables the diagnosis of EA with high levels of agreement regarding the ultrasound characteristics of EA $[9,11,15,17,21]$. In our analysis, 15 of 54 patients underwent an additional $C T$ scan without specific questioning for the diagnosis of EA, with a correct diagnosis in 5/15 (33.3\%) patients. Furthermore, EA was detected in the initial, routine, basic B-US examination in only 2/20 (10\%) patients. The missing sonographic diagnosis by the primary attending physician indicates the high interobserver variability, one of the major limitations of ultrasound diagnostics in general [29]. However, a further important reason could be the dependence of the knowledge about the disease on the clinical and sonographic experience of the ultrasound examiners. In 15/54 (28.3\%) study patients with EA confirmed by a highly qualified ultrasound examiner, the diagnosis of EA was not accepted and documented as a final clinical diagnosis. This may indicate a generally low level of trust in ultrasound diagnostics or a lack of awareness of the diagnosis of EA by the responsible physician. The most frequently mentioned misdiagnoses were unclear abdominal pain (18.5\%) and diverticulitis (5.5\%). Moreover, the lack of knowledge of the disease led to unnecessary therapeutic measures in 26/54 (48.1\%) patients. These patients underwent antibiotic therapy, hospitalization, or both. Interestingly, despite confirming the EA diagnosis, in four patients in our study, the treating physicians ordered antibiotic therapy as the therapy of choice. This reinforces again the lack of awareness of EA among physicians as a self-limiting disease that requires only symptomatic analgesic therapy $[4,12,15]$. However, we have observed a significant increase in the acceptance of the diagnosis of EA among treating physicians from 2013 onwards compared with before 2013 $(p<0.05$, Fisher's exact test). This could be interpreted as an indication of increasing knowledge and acceptance of the sonographic diagnosis of EA, apparently due to further training in our hospital.

This examination was performed in a university hospital with an interdisciplinary ultrasound center that has been established for over 30 years, performs 15000 ultrasound examinations per year, and employs experienced examiners. It must be assumed that in primary care hospitals without an interdisciplinary ultrasound center and with less qualified examiners and a lower quality of ultrasound machines, the level of knowledge of EA's clinical presentation and its clinical acceptance are even lower and the frequency of misdiagnosis is even higher. Therefore, misdiagnoses of rare diseases like EA may not be a local, but rather a general problem in the health care system. In addition, general knowledge and skills in gastrointestinal ultrasound should be considered and promoted [29].

Our study had some limitations. First, sonographic and clinical follow-up could be performed in only $n=45 / 54$ (83.3\%) patients. Despite the evidence of the importance of B-US and CEUS in the diagnosis of $E A$, the awareness of this disease in physicians in practice remains the essential requirement for diagnosis [28]. This is based on the legitimate assumption that sonography is characterized by a limited overview, high interobserver variability, high inter-device variability, examiner-dependent documentation of findings, and patient-related limitations due to obesity and meteorism $[16,30]$. In everyday clinical practice, this results in varying credibility and acceptance of "subjective" sonographic findings and "objective" CT findings [16]. Furthermore, in the retrospective evaluation, it could not be determined whether the investigator was blinded to the results of other examinations. However, this fact did not matter, because this study only investigated clinical awareness/ acceptance of EA.

\section{Conclusion}

In our retrospective study, we showed that awareness and knowledge regarding the disease of EA are extremely low. The mild or absent inflammatory parameter is an important feature of this disease and could provide helpful information for diagnosis. In the event of clinical suspicion of EA, a highly qualified sonographer should first perform a sonographic examination. If there is clinical uncertainty, a clinical sonographic follow-up should be conducted. Early detection of this disease can prevent unnecessary therapeutic and imaging measures. Therefore, this disease should be highlighted in ultrasound training for medical students and emergency medicine physicians. It must be recognized that the lack of knowledge about the clinical presentation of EA, the low diagnostic acceptance by clinicians, and the high degree of misdiagnosis in imaging present a general problem in the healthcare system.

\section{Acknowledgements}

The work of Dr. Ehsan Safai Zadeh is funded by part of a research grant from the Anneliese Pohl Foundation (Anneliese Pohl Stiftung). We acknowledge this support from the Anneliese Pohl Foundation (Anneliese Pohl Stiftung).

\section{Conflict of Interest}

The authors declare that they have no conflict of interest. 


\section{References}

[1] Goethe JW, Von Müller F Goethes Unterhaltungen mit dem Kanzler Friedrich v. Müller. J. B. Gotta'sschen; 1870

[2] Dharssi S, Wong-Rieger D, Harold M et al. Review of 11 national policies for rare diseases in the context of key patient needs. Orphanet J Rare Dis 2017; 12: 63. doi:10.1186/s13023-017-0618-0

[3] Mechler K, Rausch J, Mountford WK et al. Disease awareness or subtle product placement? Orphan diseases featured in the television series "House, M.D." - a cross-sectional analysis. BMC Med Ethics 2020; 21: 20. doi:10.1186/s12910-020-0463-x

[4] Rao PM, Rhea JT, Wittenberg J et al. Misdiagnosis of primary epiploic appendagitis. The American Journal of Surgery 1998; 81-85

[5] de Brito P, Gomez MA, Besson M et al. Fréquence et épidémiologiedescriptive de l'appendicite épiploïque primitive par l'exploration tomodensitométrique des douleurs abdominales de l'adulte. J Radiol 2008; 89: 235-243. doi:10.1016/s0221-0363(08)70399-8

[6] Mollà E, Ripollés T, Martínez M] et al. Primary epiploic appendagitis: US and CT findings.. Eur Radiol 1998; 8: 435-438. doi:10.1007| s003300050408

[7] Boardman J, Kaplan KJ, Hollcraft C et al. Radiologic-pathologic conference of Keller Army Community Hospital at West Point, the United States Military Academy: Torsion of the epiploic appendage. AJR Am J Roentgenol 2003; 180: 748. doi:10.2214/ajr.180.3.1800748

[8] Vinson DR. Epiploic appendagitis: A new diagnosis for the emergency physician. Two case reports and a review. Journal of Emergency Medicine 1999; 827-832

[9] Hollerweger A, Macheiner P, Hübner E et al. Spontane Nekrose einer Appendix epiploica: Sonographische Zeichen in 28 Fällen.. Ultraschall in Med 2002; 23: 239-244. doi:10.1055/s-2002-34057

[10] Chen J-H, Wu C-C, Wu P-H. Epiploic appendagitis: An uncommon and easily misdiagnosed disease. J Dig Dis. 2011; 12: 448-452. doi:10.1111/j.1751-2980.2011.00543.x

[11] Görg C, Egbring J, Bert T. Contrast-enhanced ultrasound of epiploic appendagitis. Ultraschall in Med 2009; 30: 163-167. doi:10.1055/s-2008-1027891

[12] Choi YU, Choi PW, Park YH et al. Clinical characteristics of primary epiploic appendagitis. J Korean Soc Coloproctol 2011; 27: 114-121. doi:10.3393/jksc.2011.27.3.114

[13] van Breda Vriesman AC, van Mol Otterloo A], de Puylaert JB. Epiploic appendagitis and omental infarction. Eur J Surg 2001; 167: 723-727. doi:10.1080/11024150152707680

[14] Sand M, Gelos M, Bechara FG et al. Epiploic appendagitis--clinical characteristics of an uncommon surgical diagnosis. BMC Surg 2007; 7: 11. doi:10.1186/1471-2482-7-11

[15] Giannis D, Matenoglou E, Sidiropoulou MS et al. Epiploic appendagitis: pathogenesis, clinical findings and imaging clues of a misdiagnosed mimicker. Ann Transl Med 2019; 7: 814. doi:10.21037/atm.2019.12.74

[16] Tamandl D, Uray T. Akutes Abdomen: Was will der Kliniker vom Radiologen wissen?. Radiologe 2019; 59: 95-105. doi:10.1007/ s00117-018-0484-3
[17] Singh AK, Gervais DA, Hahn PF et al. CT appearance of acute appendagitis. AJR Am J Roentgenol 2004; 183: 1303-1307. doi:10.2214/ajr.183.5.1831303

[18] Dietrich CF, Lembcke B, Jenssen C et al. Intestinal ultrasound in rare gastrointestinal diseases, update, part 1. Ultraschall in Med 2014; 35: 400-421. doi:10.1055/s-0034-1385154

[19] Dietrich CF, Lembcke B, Jenssen $C$ et al. Intestinal ultrasound in rare gastrointestinal diseases, update, Part 2. Ultraschall in Med 2015; 36: 428-456. doi:10.1055/s-0034-1399730

[20] Dong Y, Braden B, Klinger $C$ et al. Ultrasound findings in extragenital endometriosis. J Ultrason 2018; 18: 247-254. doi:10.15557| JoU.2018.0036

[21] Dietrich CF, Hollerweger A, Dirks K et al. EFSUMB Gastrointestinal Ultrasound (GIUS) Task Force Group: Celiac sprue and other rare gastrointestinal diseases ultrasound features. Med Ultrason 2019; 21 : 299-315. doi:10.11152/mu-2162

[22] Dirks K, Calabrese E, Dietrich CF et al. EFSUMB-Positionspapier: Empfehlungen für den gastrointestinalen Ultraschall (GIUS) bei akuter Appendizitis und Divertikulitis. Ultraschall in Med 2019; 40: 163-175. doi:10.1055/a-0824-6952

[23] Hollerweger A, Maconi G, Ripolles T et al. Gastrointestinaler Ultraschall (GIUS) bei intestinalen Notfällen - Ein EFSUMB-Positionspapier. Ultraschall in Med 2020; doi:10.1055/a-1147-1295

[24] Maconi G, Nylund K, Ripolles T et al. EFSUMB-Empfehlungen und klinische Leitlinien für den gastrointestinalen Ultraschall (GIUS) chronisch entzündlichen Darmerkrankungen (CED). Ultraschall in Med 2018; 39: 304-317. doi:10.1055/s-0043-125329

[25] Nylund K, Maconi G, Hollerweger A et al. EFSUMB-Empfehlungen und Leitlinien des Gastrointestinalen Ultraschalls - Teil 1: Untersuchungstechniken und Normalbefund (Langversion). Ultraschall in Med 2017; 38: e1-e15. doi:10.1055/s-0042-115853

[26] Nuernberg D, Saftoiu A, Barreiros AP et al. EFSUMB recommendations for gastrointestinal ultrasound part 3: Endorectal, endoanal and perineal ultrasound. Ultrasound Int Open 2019; 5: E34-E51. doi:10.1055/a-0825-6708

[27] Sidhu PS, Cantisani V, Dietrich CF et al. Die EFSUMB-Leitlinien und Empfehlungen für den klinischen Einsatz des kontrastverstärkten Ultraschalls (CEUS) bei nicht-hepatischen Anwendungen: Update 2017 (Langversion). Ultraschall in Med 2018; 39: e2-e44. doi:10.1055/a-0586-1107

[28] Hasbahceci M, Erol C, Seker M. Epiploic appendagitis: Is there need for surgery to confirm diagnosis in spite of clinical and radiological findings? World J Surg 2012; 36: 441-446. doi:10.1007/s00268-011$1382-2$

[29] Heese F, Görg C.. Diagnostische Wertigkeit einer internistischen Referenzsonographie (DEGUM-Stufe 3). Ultraschall in Med 2006; 27 : 220-224. doi:10.1055/s-2006-926665

[30] Amann-Vesti B, Bönhof JA, Görg C. Sonografie kompetent. Von der Indikation zur Interpretation. Stuttgart, New York: Georg Thieme Verlag; 2016 